\title{
Toward CFD-DEM simulations of the blast furnace raceway
}

\author{
Francis Romano*†, Edouard Izard* and Pascal Fede ${ }^{\dagger}$ \\ * ArcelorMittal Maizières Research SA \\ Voie Romaine, 57280 Maizières-lès-Metz, France \\ ${ }^{\dagger}$ Institut de mécanique des fluides de Toulouse (IMFT) \\ 2 all Prof Camille Soula, 31400 Toulouse, France
}

\begin{abstract}
Gas injections at the bottom of the blast furnace create void regions in the coke matrix called the raceways which play a role in the gas distribution in the furnace and is directly linked to the iron production. In this region, complex physical phenomena occur, including particle-fluid with combustion, and, to our knowledge, there is no consensus on its shape and dynamics as well as its creation and stability. A better understanding of the raceway region could lead to a more efficient and stable blast furnace process. An unresolved CFD-DEM approach is used to study the gas-solid flows where coke particles are modelled as a discrete phase and the gas as continuous solving the RANS modelling of the turbulence [1]. In order to clarify the main phenomena occurring in the raceway dynamics, we develop a CFD-DEM model of a $1 / 5$ scale $2 \mathrm{~d}$ slot pilot of the blast furnace [2] for which alternative raceway collapses are monitored. First, DEM simulations are realized without the fluid contribution and shows that the pilot geometry influences the mechanical load applied on the raceway with a saturation of the granular stress inside the pilot. Also, dry raceway collapse shows a modification of this stress in a short characteristic time. Then, CFD-DEM model of the pilot permits to investigate the gas and granular flows when the raceway is imposed as in the experiment. The dynamics of the collapse with the coupling is solved and displays a complex particle-gas $3 \mathrm{~d}$ flow (Fig 1). Further implementation in the model will allow coke particle combustion.
\end{abstract}

Particles velocity magnitude

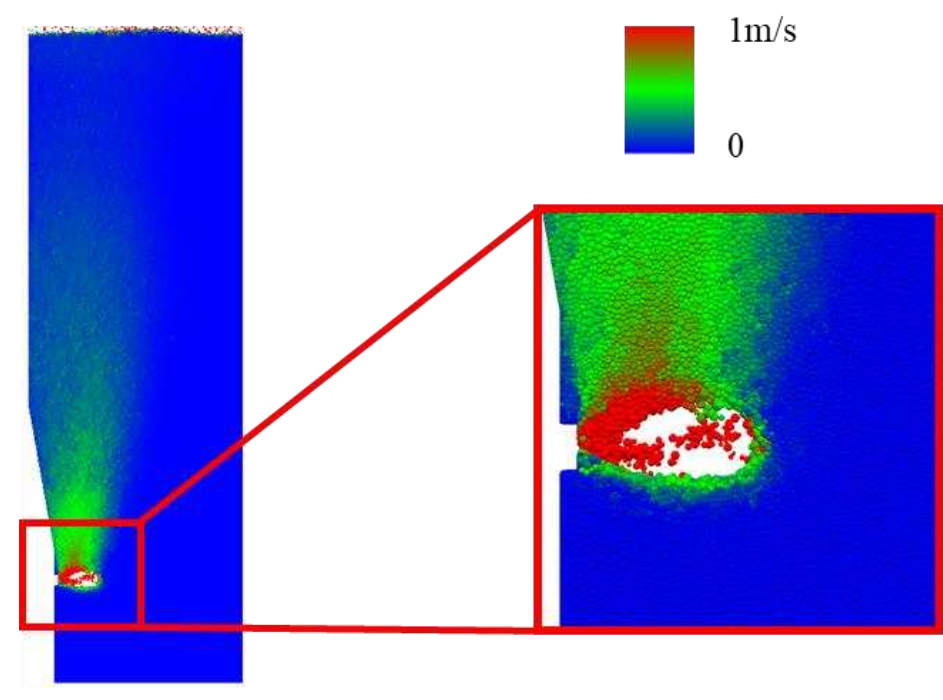

Fluid velocity field

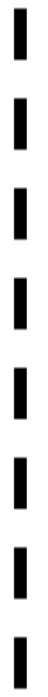

Fig 1 : CFD-DEM simulation of raceway collapsing.

\section{REFERENCES}

[1] Zhou, Z. Y., Kuang, S. B., Chu, K. W., \& Yu, A. B. (2010). Discrete particle simulation of particle-fluid flow: model formulations and their applicability. Journal of Fluid Mechanics, 661, 482-510.

[2] Lectard, E., DANLOV, G., Blacknik, W., \& MüLHEIMS, K. (2005). Optimisation of blast furnace raceway at high injection rates. EUR, (21691), 1-150. 